\title{
Fast Food Industry Growth in China
}

\section{Entesar Ahmed \\ University of Wollongong in Dubai (UOWD)}

\section{Introduction:}

Over the last decade, fast food industries in china have dramatically increased. Several international enterprises have moved and expand their brands in china markets and tradeholders since 1990. This paper will discuss the Chinese fast food consumption and supply and will give account to the factors affecting it favorably like the increase in household income, changes in Chinese lifestyle, growth in population size, emergence of many foreign brands and players, technological advancement, and the introduction of franchising regulations. It will also highlighted on the increasing health concerns which could possibly affect the Chinese fast food consumption and supply in the longer run. The paper will also talk about the elasticity of demand and how the availability of many substitutes will make demand highly elastic in the Chinese fast food industry, which shall imply that any slight change in prices of fast food products by any company will affect demand for that company's product adversely to other substitutes / company products. Finally it will discuss the Chinese fast food non-collaborative oligopolistic market structure.

\section{Analysis:}

China is prominent market that attracts major international companies to take part in its economic development. It has a population of 1.378 billion in 2016 , which accounts for $27 \%$ growth over 1987. Relatively, the overall economy has witnessed dramatic growth by $4003 \%$ during the period from 1987 to 2016, according to World Bank statistics (Wei et al., 2017). 
This have urged the international fast food players to enter the Chinese market. Now the Chinese fast food industry generates USD 150.9 billion in 2017 which accounts for $9.6 \%$ growth over 2016, according to Estimates by IBISWorld (IBISWorld ,2017). Below we will exhibit this industry and factors affecting it.

\section{Demand and supply:}

Factors affecting demand positively:

According to a study by the reserve bank of Australia, the real household incomes in China have averaged annual growth of $10 \%$ over the past two decades (Stratford and Cowling, 2016). As household income increases, disposable income increase as well which shall affect the society's demand for fast food and make them shift towards more comfortable ways of living, hence they will spend more on readymade food. Additionally, Chinese life style is getting faster with urbanization and industrialization. The economic reforms that began in the late 1970s has increased the rural-urban migration and after the accession of China to the World Trade Organization in 2001 it has even accelerated. Over past decade, the share of population living in an urban areas increased by $13 \%$ to $50 \%$ (Rush, 2011). Also the dependency ratio has dropped from near 80s\% in 1975 to near 40s\% in 2010.

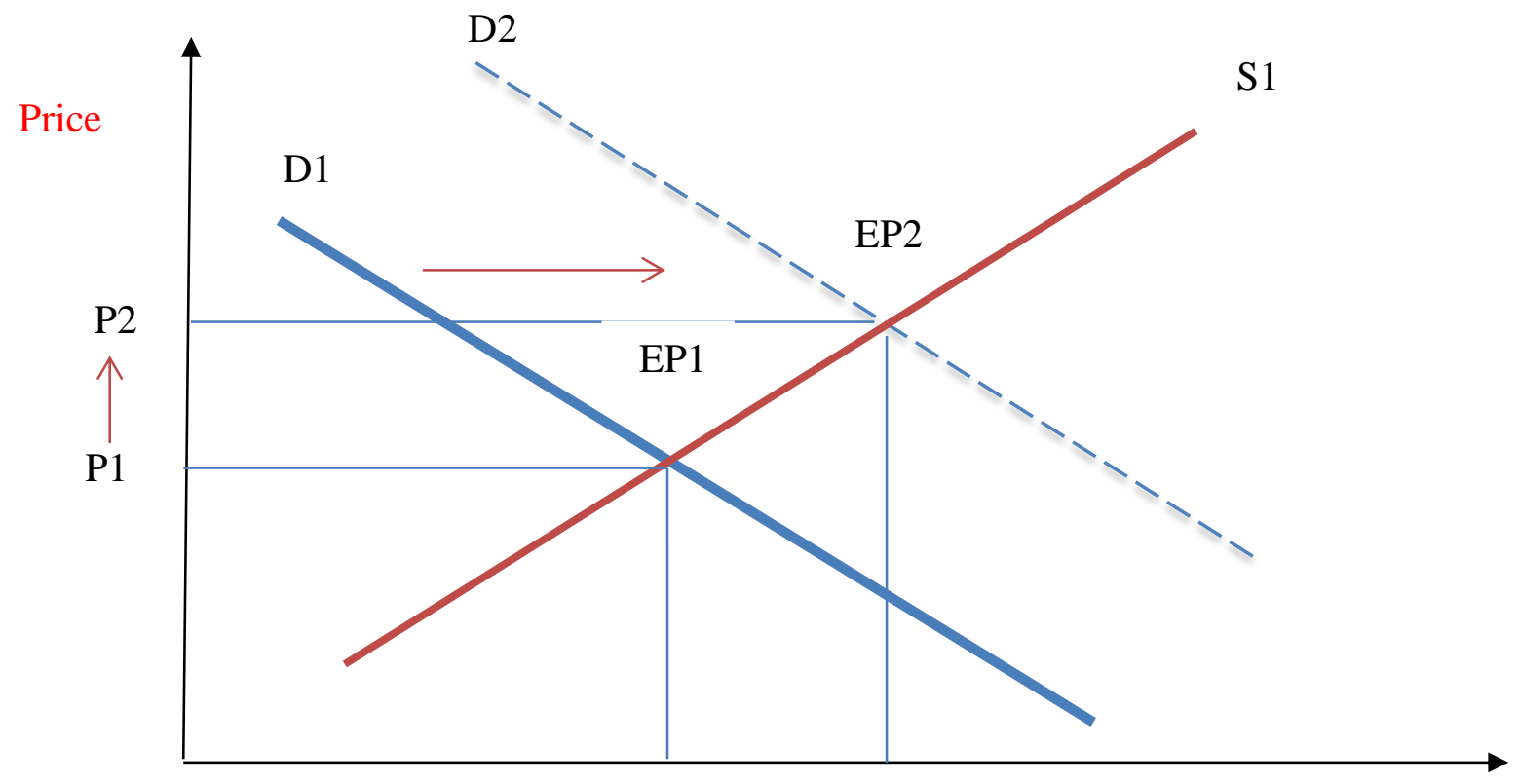

Q1 $\longrightarrow$ Q2 Quantity demanded and supplied per period 


\section{Shift in a demand curve}

According to the above, demand is shifting to the right which will stimulate growth in market size, and accordingly equliperium price and quantity will be higher.

\section{Factors affecting supply positively:}

First foreign fast food brand entering the Chinese market was KFC in 1987, followed by McDonald's which opened its first branch in 1990 (Yan, 2013). These two companies are now dominating the Chinese fast food market with nearly $70 \%$ market share in 2012 (Roth et al., 2008). This has introduced new type of products and tastes. Furthermore, the Western fast food companies have introduced new concepts of chain restaurants management, advanced business models, quality operations and services, cleanliness standards, process efficiency, hourly employment system, successful staff training, modern marketing and promotion techniques, etc. Additionally, franchising law has been introduced in China in 2005 which have lowered the barriers of entry into the Chinese market and facilitated the emergence of new players into the market.

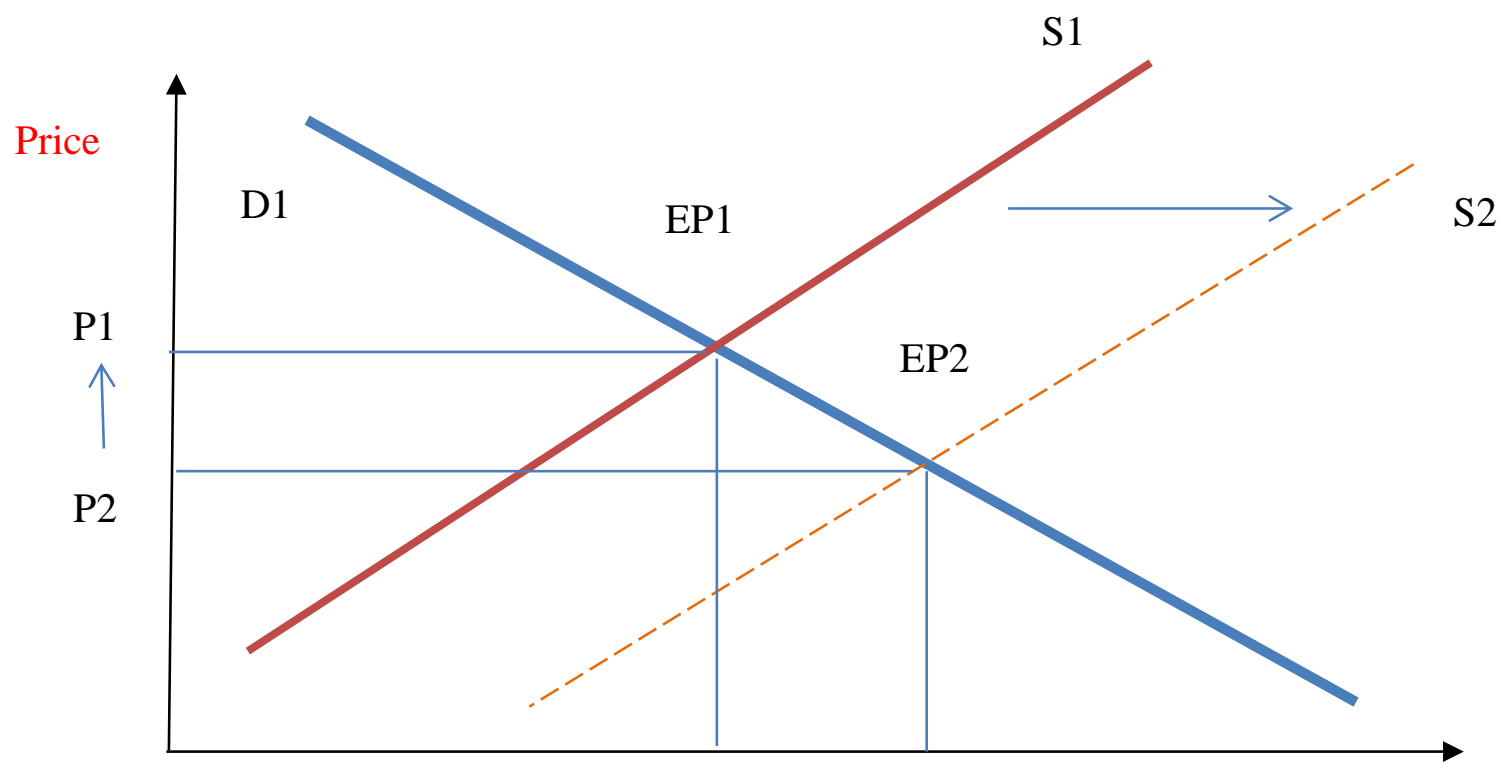

Q1 $\longrightarrow$ Q2 Quantity demanded and supplied per period 
According to above factor, supply is shifting to the right, and accordingly the quantity supplied will be higher and the equliperium price will decline.

However, health concerns on fast food products shall exert a negative force on development of this market in the long run. The fast food served by the Western brands has low-nutrient, and is high in sugar and saturated fats, which increases the risk of obesity, diabetes, blood pressure, etc. China has now become the largest country worldwide in terms of overweight population, with around 43 Million obese men (10.8\%) and 46 million obese women (14.9\%) (Wang et al., 2007). The Chinese consumer is becoming more concerned about food safety. According to survey by McKinsey \& Company on 10,000 consumer from 44 different Chinese cities, the number of Chinese consumers willing to buy western fast food has dropped by $16 \%$ from the period 2012 to 2015 (Zipser et al., 2016). To respond to health risks presented by fast food products, the central government in China has introduced a plan called Healthy China 2030 which aims to make China a healthy state by 2030 (Tan et al., 2017). The plan will include the introduction of health education into school curriculum to promote "health as habit".

\section{Elasticity of Demand:}

The Chinese fast food industry is dominated by few main companies like Yum Brands (KFC \& Pizza Hut \& etc.), McDonalds, Taiwanese restaurant chain called Dicos, and Master Kong which is serving local-style fast food, etc (Zhu, 2006). This business environment provides variety of substitutes to customers which will make the fast food products highly elastic for any change in price. Hence any increase in price will have an adverse effect on the demand curve which will lead to decrease in quantity demanded drastically. 


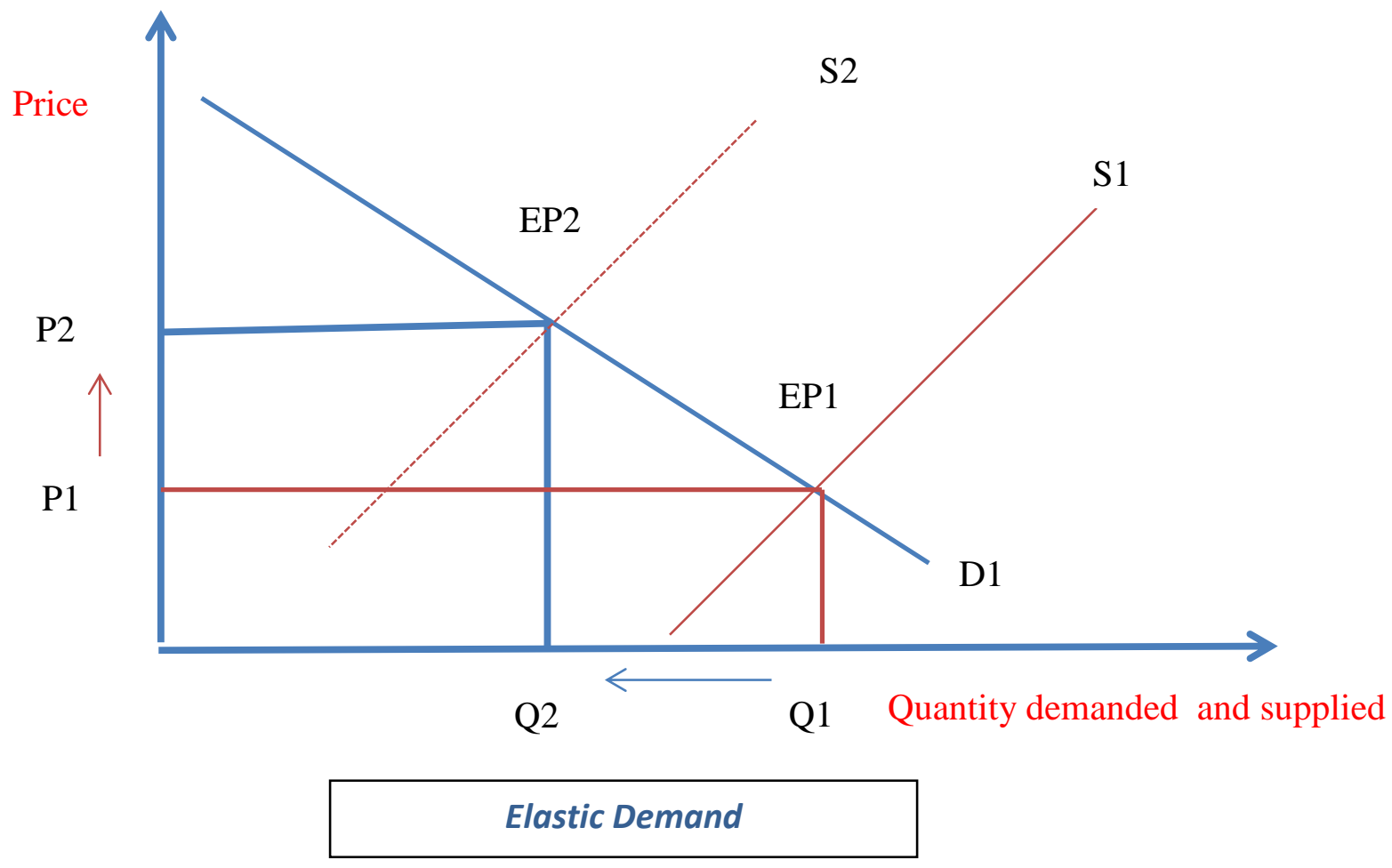

\section{Market structure (Oligopoly) :}

The strong competition between the big brands especially KFC and McDonalds led to open new branches in most cities in china. This competition also stimulated the start of new domestic fast food restaurants. These companies compete with each other to gain bigger share of the market and they would implement different strategies to arrive their objective.

This represents a non-collusive oligopoly market structure. Due to the fierce competition in the Chinese fast food industry to gain market share, many companies choose to compete by following standardisation and localisation strategies (Watson, 2006). Companies are less likely to follow products' price increase because of consumer's price sensitivity. 
However they are more likely to respond to price reduction to maintain market share. This represents a kinked demand curve model. For instance, KFC and McDonald are adapting to the Chinese consumers' price and had to reduce price of the Best of Menu product from 7 Euros in Europe to equivalent 2.3 Euros in China. This indicates that companies will not follow an increase in products price, but will more likely follow decrease in market prices.

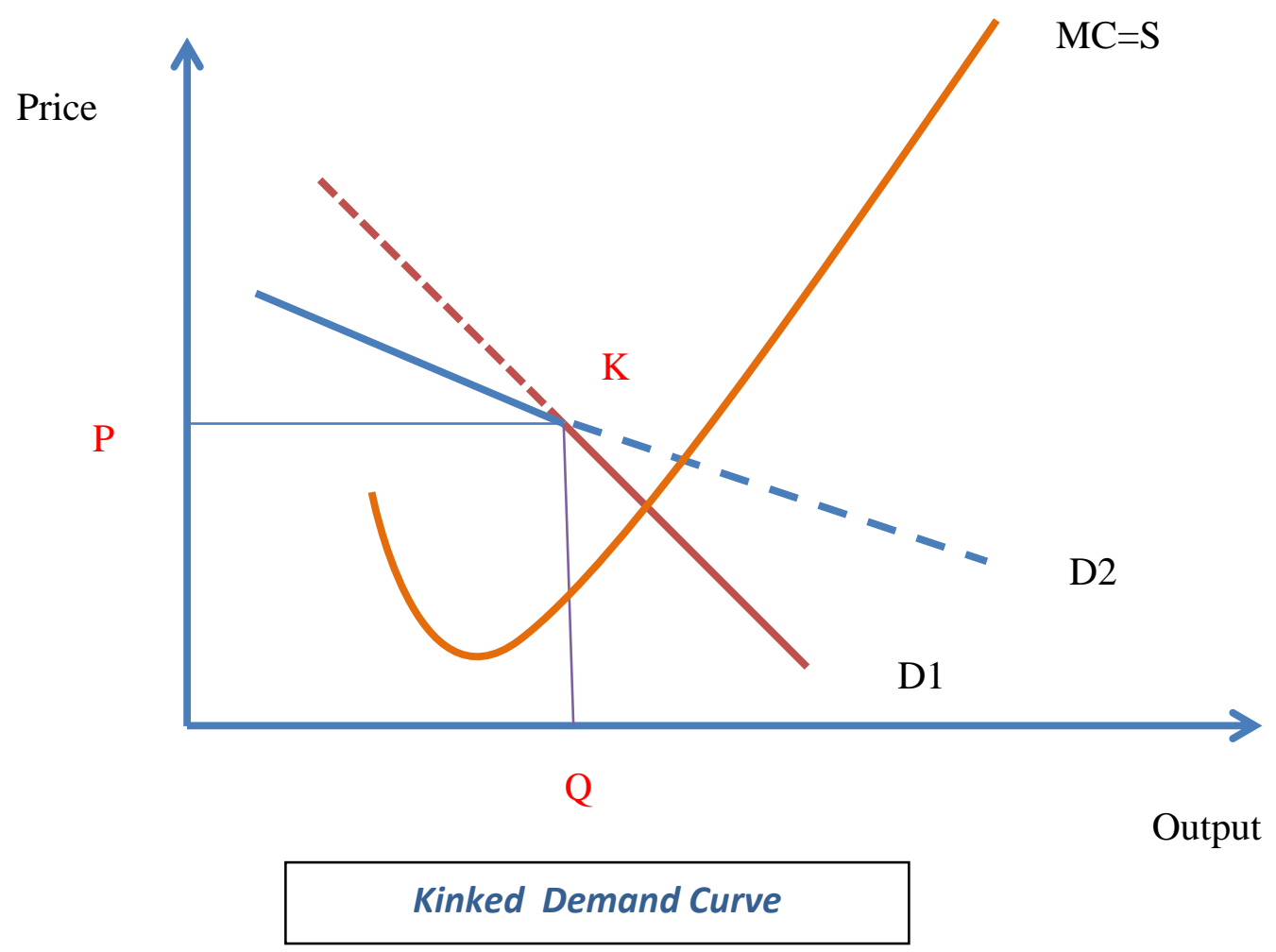

\section{Conclusion:}

This study has shown the fast food industry in China and discussed the factors affecting the demand and supply. It suggests that the market enjoys a non-collusive oligopoly and is elastic in terms of demand and supply due the presence of many competitors and substitutes. The demand and supply is expanding however health concerns could exert negative pressure on the curve. 


\section{References:}

[1] WEI, S.-J., XIE, Z. \& ZHANG, X. 2017. From" Made in China" to" Innovated in China": Necessity, Prospect, and Challenges. Journal of Economic Perspectives, 31, 49-70.

[2] IBISWorld 2017, Fast-Food Restaurants, China Market Research Report. Available from: IBISWorld.[July 2017].

[3] Al-Shargie, Fares, Masashi Kiguchi, Nasreen Badruddin, Sarat C. Dass, Ahmad Fadzil Mohammad Hani, and Tong Boon Tang. "Mental stress assessment using simultaneous measurement of EEG and fNIRS." Biomedical optics express 7, no. 10 (2016): 3882-3898.

[4] Al-Shargie, F. M., Tong Boon Tang, Nasreen Badruddin, and Masashi Kiguchi. "Mental stress quantification using EEG signals." In International Conference for Innovation in Biomedical Engineering and Life Sciences, pp. 15-19. Springer, Singapore, 2015.

[5] Al-Shargie, Fares, Tong Boon Tang, and Masashi Kiguchi. "Assessment of mental stress effects on prefrontal cortical activities using canonical correlation analysis: an fNIRS-EEG study." Biomedical optics express 8, no. 5 (2017): 2583-2598.

[6] STRATFORD, K. \& COWLING, A. 2016. Chinese Household Income, Consumption and Savings. RBA Bulletin,(September), 31-40.

[7] RUSH, A. 2011. China's Labour Market. Reserve Bank of Australia. Bulletin, September Quarter.

[8] Al-Shargie, Fares, Tong Boon Tang, and Masashi Kiguchi. "Stress assessment based on decision fusion of EEG and fNIRS signals." IEEE Access 5 (2017): 19889-19896.

[9] Al-Shargie, Fares, Tong Boon Tang, Nasreen Badruddin, and Masashi Kiguchi. "Towards multilevel mental stress assessment using SVM with ECOC: an EEG approach." Medical \& biological engineering \& computing 56, no. 1 (2018): 125-136.

[10] Al-shargie, Fares, Tong Boon Tang, and Masashi Kiguchi. "Mental stress grading based on fNIRS signals." In 2016 38th Annual International Conference of the IEEE Engineering in Medicine and Biology Society (EMBC), pp. 5140-5143. IEEE, 2016.

[11] Al-shargie, Fares, Tong Boon Tang, Nasreen Badruddin, and Masashi Kiguchi. "Simultaneous measurement of EEG-fNIRS in classifying and localizing brain activation to mental stress." In 2015 IEEE International Conference on Signal and Image Processing Applications (ICSIPA), pp. 282-286. IEEE, 2015.

[12] Al-Shargie, Fares. "Early Detection of Mental Stress Using Advanced Neuroimaging and Artificial Intelligence." arXiv preprint arXiv:1903.08511 (2019).

[13] Mohamed, Eltaf Abdalsalam, Mohd Zuki Yusoff, Ibrahim Khalil Adam, Elnazeer Ali Hamid, Fares Al-Shargie, and Muhammad Muzammel. "Enhancing EEG Signals in Brain Computer Interface Using Intrinsic Time-Scale Decomposition." In Journal of Physics: Conference Series, vol. 1123, no. 1, p. 012004. IOP Publishing, 2018.

[14] Al-shargie, Fares, Tong Boon Tang, Nasreen Badruddin, Sarat C. Dass, and Masashi Kiguchi. "Mental stress assessment based on feature level fusion of fNIRS and EEG signals." In 2016 6th International Conference on Intelligent and Advanced Systems (ICIAS), pp. 1-5. IEEE, 2016.

[15] Al-Shargie, Fares. "Multilevel Assessment of Mental Stress using SVM with ECOC: An EEG Approach." (2019).

[16] Al-Yoonus, Murthad, M. F. L. Abdullah, Mohammed Saeed Jawad, and Fares Al-Shargie. "Enhance quality control management for sensitive industrial products using 2D/3D image processing algorithms." In 
2014 Electrical Power, Electronics, Communicatons, Control and Informatics Seminar (EECCIS), pp. 126-131. IEEE, 2014.

[17] YAN, Y. 2013. Of hamburger and social space: Consuming McDonald's in Beijing. Food and culture: A reader, $449-471$.

[17] Al-Shargie, Fares. "Assessment of Mental Stress Using EEG and fNIRS Features." (2019).

[18] Jawad, Mohammed Saeed, Fares Al-Shargie, Murthad Al-Yoonus, and Zahriladha bin Zakaria. "Performance Analysis Comparative Study of Fingerprint Recognition Systems." Computers and Software (2014): 1154.

[19] Al-Shargie, Fares. "Quantification of Mental Stress using fNIRS Signals." (2019).

[20] Al-Shargie, Fares. "Fusion of fNIRS and EEG Signals: Mental Stress Study." (2019).

[21] Amalarethinam, DI George, P. Muthulakshmi, Mohammed Saeed Jawad, Fares Al-Shargie, Murthad AlYoonus, Zahriladha bin Zakaria, Sampath Prakasam et al. "Computers and Software." (2014).

[23] Al-Shargie, Fares, Usman Tariq, Hasan Mir, Hamad Alawar, Fabio Babiloni, and Hasan Al-Nashash. "Vigilance decrement and enhancement techniques: a review." Brain sciences 9, no. 8 (2019): 178.

[24] Al-Shargie, Fares. "Assessment of Mental Stress among Undergraduate Students Using Novel Fusion Method on EEG and fNIRS Features." (2019).

[25] Al-Shargie, Fares. "Stress Detection and Reduction Based on Simultaneous Measurement of EEG and fNIRS Signals." (2019).

[26] ROTH, A. V., TSAY, A. A., PULLMAN, M. E. \& GRAY, J. V. 2008. Unraveling the food supply chain: strategic insights from China and the 2007 recalls. Journal of Supply Chain Management, 44, 22-39.

[26] Al-Shargie, Fares. "Vigilance Enhancement Using Traditional Methods: A Review." (2019).

[27] Al-Shargie, Fares. "Vigilance Enhancement Using Computerized Techniques." (2019).

[28] Al-Shargie, Fares, and CM GOH. "Cognitive Enhancement Techniques and Their Impact on Performance Improvements: A Review." (2019).

[28] WANG, Y., MI, J., SHAN, X., WANG, Q. J. \& GE, K. 2007. Is China facing an obesity epidemic and the consequences? The trends in obesity and chronic disease in China. International journal of obesity, $31,177$.

[29] Al-Shargie, Fares, U. Tariq, M. Alex, H. Mir, and H. Al-Nashash, "Emotion Recognition Based on Fusion of Local Cortical Activations and Dynamic Functional Networks Connectivity: An EEG Study," IEEE Access, vol. 7, pp. 143550-143562, 2019.

[29] ZIPSER, D., CHEN, Y. \& GONG, F. 2016. Here comes the modern Chinese consumer. Pobrane czerwiec.

[30] TAN, X., LIU, X. \& SHAO, H. 2017. Healthy China 2030: a vision for health care. Value in health regional issues, $12,112-114$.

[31] ZHU, H. 2006. Fast food in a Chinese provincial city: a comparative analysis. Texas A\&M University.

[32] WATSON, J. L. 2006. Golden arches east: McDonald's in East Asia, Stanford University Press. 